\title{
Educational and Relational Stressors Associated with Burnout in Korean Medical Students
}

\author{
Ji-Hyun Seo', Hye Jung Kim², Bong-Jo Kim³ ${ }^{3}$, So-Jin Lee ${ }^{3}$, and Hwa-ok Bae ${ }^{4} \bowtie$ \\ ${ }^{1}$ Department of Medical Education and Pediatrics, School of Medicine, Gyeongsang National University, Jinju, Republic of Korea \\ ${ }^{2}$ Department of Pharmacology, School of Medicine, Gyeongsang National University, Jinju, Republic of Korea \\ ${ }^{3}$ Department of Psychiatry, School of Medicine, Gyeongsang National University, Jinju, Republic of Korea \\ ${ }^{4}$ Department of Social Welfare, Gyeongsang National University, Jinju, Republic of Korea
}

Objective This study aimed to examine whether educational stressors and relational stressors are associated with burnout in medical students and to test social support as a moderator between stressors and burnout.

Methods A total of 263 medical students attending Gyeongsang National University composed the study sample. A standardized questionnaire was used to investigate educational and relational stressors, three dimensions of burnout, and social support of medical students.

Results The findings showed that overall burnout is very high among Korean medical students, with $9.9 \%$ totally burned out. Educational and relational stressors were significantly associated with the risk of burnout in medical students after controlling for socio-demographics and health behaviors. Social support moderated educational and relational stressors on personal accomplishment, but did not moderate stressors on emotional exhaustion and depersonalization.

Conclusion Burnout level is substantially high among Korean medical students. Educational and relational stressors are significantly associated with burnout risk in Korean medical students. Social support had moderated educational and relational stressors on personal accomplishment. The results suggest that more social support for medical students is needed to buffer stressors on and burnout.

Psychiatry Investig 2015;12(4):451-458

Key Words Burnout, Medical students, Stressors, Social support.

\section{INTRODUCTION}

Medical students are known to have a substantially lower mental quality of life than similar-age individuals in the general population. ${ }^{1-3}$ Up to $50 \%$ of medical students experience burnout, 25\% have depression, and many suffer from chronic anxiety and a poor mental quality of life. ${ }^{3,4}$ The prevalence of depression (6.5\%) is also higher in medical students compared to other college students in Korea. ${ }^{5}$ Distress in medical students is associated not only with education-related stressors such as workload, competition, sleep deprivation, the emotional impact of the dissection course, or the suffering and

Received: November 13, 2014 Revised: February 17, 2015

Accepted: April 23, 2015 Available online: September 30, 2015

$\triangle$ Correspondence: Hwa-ok Bae, PhD

Department of Social Welfare, College of Social Sciences, Gyeongsang National University, 501 Jinju-daero, Jinju 52828, Republic of Korea

Tel: +82-55-772-1245, Fax: +82-55-772-1219, E-mail: hobae@gnu.ac.kr

(c) This is an Open Access article distributed under the terms of the Creative Commons Attribution Non-Commercial License (http://creativecommons.org/licenses/by$\mathrm{nc} / 3.0$ ) which permits unrestricted non-commercial use, distribution, and reproduction in any medium, provided the original work is properly cited. dying of patients $s^{3,6,7}$ but also with relational stressors such as discord with faculty, peers, or classmates ${ }^{8,9}$ and work-family conflicts. ${ }^{10}$ In Korea, the experience of failure (drop-out) during medical school has been reported to make students feel as if their status has declined, their self-concept has changed, and their social network has become restricted. ${ }^{11}$

Burnout is defined by Maslach and his colleagues as a pathologic syndrome in response to chronic interpersonal stressors on the job. ${ }^{12}$ Burnout can be a predictor of psychological impairments such as depression and low self-esteem among medical students. ${ }^{13,14}$ Burnout can also lead to medical students' dropping out of school and to suicidal ideation. ${ }^{4}$ In contrast, students who are resilient to burnout are less likely to experience other dimensions of distress and are more likely to have a higher quality of life. ${ }^{15}$ Although burnout is prevalent among medical students, only a small proportion of medical students with depression use mental health services. ${ }^{16}$ Social support, including faculty, family, and friends, has been found to be one of the most crucial factors for dealing with stress and psychological impairments in medical students. ${ }^{17,18}$ Students who 
perceive higher levels of social support are more likely to be resilient to and to recover from burnout than other students. ${ }^{15}$

As the medical education system in Korea is competitive and performance-driven, it is presumed that Korean medical students may experience high levels of burnout, as is observed in other countries. Further, medical students who have tensions with faculty or peers may experience the high level of burnout observed in other countries. The main objectives of this study were to examine association between educational and relational stressors and burnout, and to examine social support as a moderator between stressors and burnout in medical students. Therefore, it is hypothesized that educational and relational stressors will be associated with an increased level of burnout (H1), and social support will moderate the association between stressors and burnout $(\mathrm{H} 2)$.

\section{METHODS}

\section{Setting and sampling}

A cross-sectional survey was conducted at the Medical School of Gyeongsang National University (GNU), which is located at Jinju in South Korea. In 2006, GNU changed from a College of Medicine to a Medical School. The curriculum of the Medical School of GNU is similar to that of other Korean Medical Schools: Preclinical training (first-year and secondyear students) and clinical training (third-year and fourth-year students). Preclinical training is composed of lecture, laboratory experiments, frequent written exams, and clinical training composed mainly of rotations through hospital clinical departments. The first-year students learn basic medical science and take four mid-term and final exams. The secondyear students take 16 integrated courses along with exams every two or three weeks. The third-year students who rotate through clinical departments have only one exam at the end of the clinical clerkship. The fourth-year students who graduate with taking three integrated exams after completing 10week clinical practice courses are qualified for the National Licensing Examination.

All medical students from first year to fourth year in the Medical School of GNU (total number=320) were invited to complete the survey in the autumn of 2013. Two hundred and sixty-three medical students (82.2\%) participated in the self-administered survey utilizing a standardized questionnaire. All of them were graduate students. Participation was voluntary, and the answers to the survey were anonymous.

The survey questions assessed demographics and health characteristics, burnout, educational and relational stressors, and social support. School year, sex, religion, educational environment, and social support have been found to be associated with burnout in previous studies. ${ }^{15-18}$ The current study constructed a research model positing educational and relational stressors as independent variables, socio-demographics and health characteristics as control variables, burnout as the dependent variable, and social support as a moderating variable.

\section{Measurement}

The survey used the Maslach Burnout Inventory $(\mathrm{MBI})^{19}$ to identify burnout. To measure three dimensions of burnoutemotional exhaustion (EE), depersonalization (DP), and personal accomplishment (PA)-the survey utilized seven items for EE, five items for DP, and seven items for PA. Reliability analyses indicated a high level of internal consistency for EE $(0.85)$ and for PA (0.80), but only a fair level for DP (0.67). Responses were scored on a 5-point scale ranging from 0 (never) to 4 (always). The degree of burnout was categorized in accordance with Galán et al.s study, ${ }^{20}$ as follows: low $\leq 13$, moderate $14-18$, and high $\geq 19$ on EE; low $\leq 7$, moderate 8-9, and high $\geq 10$ on DP; and low $\geq 18$, moderate $15-17$, and high $\leq 14$ on PA.

Similar to other relevant studies, this study included 11 items examining educational stressors such as "feeling burdened with absolute amount of study" and "feeling worried about possible drop-out." This study also included five items on relational stressors such as "keeping a good relationship with peers" and "feeling discriminated against by faculty" (Refer to Supplementary Table 1 in the online-only Data Supplement). Each item used a 5-point scale so that participants indicated their degree of stress ranging from 0 (strongly disagree) to 4 (strongly agree). Reliability analyses revealed a moderate level of internal consistency for items on educational stressors (0.78) and items for relational stressors (0.70).

This study included social support as a moderator that may moderate the association between educational and relational stressors and burnout. Social support was measured by the 12-item Multidimensional Scale of Perceived Social Support (MSPSS), ${ }^{22}$ with each item scored on a 5-point scale ranging from 0 (strongly disagree) to 4 (strongly agree). Reliability analysis found a very high level of internal consistency (0.91). This study assessed socio-demographics such as sex, school year, marital status, religion, and health characteristics such as self-rated health, drinking, smoking, and sleeping time, which may be associated with burnout as control variables. This study additionally included financing of the educational expense as one of the control variables.

\section{Statistical analysis}

This study conducted reliability tests for all the measurements and then conducted univariate analyses to estimate burnout level and to examine socio-demographics and health characteristics of the survey participants. Further, bivariate 
Table 1. Socio-demographics and health characteristics of survey participants $(\mathrm{N}=263)$

\begin{tabular}{|c|c|c|}
\hline Variable & $\mathrm{N}$ & $\%$ \\
\hline \multicolumn{3}{|l|}{ Sex } \\
\hline Male & 141 & 53.6 \\
\hline Female & 122 & 46.4 \\
\hline \multicolumn{3}{|l|}{ Age (years) } \\
\hline$<25$ & 32 & 12.2 \\
\hline $25-30$ & 190 & 72.2 \\
\hline$>30$ & 41 & 15.6 \\
\hline \multicolumn{3}{|l|}{ School year } \\
\hline 1 & 77 & 29.3 \\
\hline 2 & 77 & 29.3 \\
\hline 3 & 57 & 21.7 \\
\hline 4 & 52 & 19.8 \\
\hline \multicolumn{3}{|l|}{ Marital status* } \\
\hline Single (not married, divorced) & 233 & 89.3 \\
\hline Married & 28 & 10.7 \\
\hline \multicolumn{3}{|l|}{ Major at undergraduate } \\
\hline Humanities, social sciences, law, etc. & 13 & 4.9 \\
\hline Biology, nutrition, natural sciences, etc. & 169 & 64.3 \\
\hline Nursing, pharmacology, veterinary, etc. & 41 & 15.6 \\
\hline Veterinary medicine & 31 & 11.8 \\
\hline Other departments & 9 & 3.4 \\
\hline \multicolumn{3}{|l|}{ Religion* } \\
\hline Buddhism & 26 & 10.2 \\
\hline Christianity & 84 & 33.1 \\
\hline Catholic & 38 & 15.0 \\
\hline Other religion & 2 & 0.8 \\
\hline No religion & 104 & 40.9 \\
\hline \multicolumn{3}{|l|}{ Financing source for education* } \\
\hline Self & 19 & 10.3 \\
\hline Parent(s) & 113 & 61.1 \\
\hline Other family member & 4 & 2.7 \\
\hline Loan or debt & 48 & 25.9 \\
\hline \multicolumn{3}{|l|}{ Self-rated health status } \\
\hline Very bad & 44 & 16.7 \\
\hline Bad & 120 & 45.6 \\
\hline Average & 78 & 29.7 \\
\hline Good & 18 & 6.8 \\
\hline Very good & 3 & 1.1 \\
\hline \multicolumn{3}{|l|}{ Drinking* } \\
\hline Drinking (regardless regularity) & 196 & 75.7 \\
\hline No drinking & 63 & 24.3 \\
\hline \multicolumn{3}{|l|}{ Smoking* } \\
\hline Smoking (regardless regularity) & 27 & 10.4 \\
\hline No smoking & 233 & 89.6 \\
\hline
\end{tabular}

Table 1. Socio-demographics and health characteristics of survey participants ( $\mathrm{N}=263)$ (continued)

\begin{tabular}{lrr}
\hline \multicolumn{1}{c}{ Variable } & $\mathrm{N}$ & $\%$ \\
\hline Sleeping time a day $(\mathrm{hr} .)^{*}$ & & \\
$<5$ & 89 & 34.0 \\
$5-7$ & 149 & 56.9 \\
$>8$ & 24 & 9.2 \\
Total & 263 & 100.0 \\
\hline
\end{tabular}

*there are a few missing responses for marital status, religion, financing source for education, drinking, smoking, and sleeping time, but were excluded from the total percentages

analyses were conducted to examine the association between variables, using t-test and ANOVA. Lastly, this study conducted multivariate regression analyses to examine whether educational and relational stressors are associated with burnout level of medical students after controlling for other variables and used hierarchical regression analyses to test whether social support moderates the association between stressors and burnout. Data were analyzed using SPSS 15.0 for Windows.

\section{RESULTS}

\section{Sample characteristics}

Out of the 263 survey respondents, more than half were men (53.6\%). Respondents were aged between 22 and 40 years old with mean age 25.7. Respondents were enrolled in the first year (29.3\%), second year (29.3\%), third year (21.7\%), and fourth year (19.8\%) of medical school. Approximately 10\% (10.7\%) were married. Respondents had graduated college with majors in biology, nutrition, and natural sciences (64.3\%), nursing and pharmacology (15.6\%), veterinary medicine (11.8\%), and humanities, social sciences, and other departments (8.3\%). Respondents reported the following religions: Christianity (33.1\%), Catholicism (15.0\%), Buddhism (10.2\%), and other religions ( $0.8 \%$ ), while $40.9 \%$ reported no religion. Financing of their education came from parents (61.1\%), family members (2.7\%), self (10.3\%), and loan or debt (25.9\%). The majority rated their health as bad (45.6\%) and very bad (16.7\%), and only $1.1 \%$ rated their health as very good. Three-fourths (75.7\%) reported drinking, whereas $89.6 \%$ denied smoking. More than half of the respondents (56.9\%) slept between 5 and 7 hours per day, whereas only $9.2 \%$ reported sleeping more than 8 hours per day (Table 1).

\section{Burnout level}

A significant proportion of students reported high levels of burnout: $28.1 \%$ for EE ( $\geq 19), 40.4 \%$ for DP $(\geq 10)$, and $40.8 \%$ for PA $(\leq 14)$ (Table 2). Thirty-four percent of the students reported at least two dimensions of high burnout. Sixteen per- 
cent of students suffered from both EE and DP, and 13.7\% from both EE and PA, whereas $24.3 \%$ suffered from both DP and PA. The students who reported all three dimensions of high burnout, i.e., "totally burned out," accounted for $9.9 \%$ of the total.

Bivariate analyses revealed that four factors among the socio-demographic characteristics and health behaviors were significantly associated with burnout in medical students. Female students reported slightly higher mean scores for EE $(\mathrm{p}<0.01)$ and lower mean scores for PA $(\mathrm{p}<0.05)$ than male students, signifying that female students experience higher burnout than male students. Students in the second year re- ported the highest mean scores for EE and DP $(\mathrm{p}<0.05, \mathrm{p}<$ $0.05)$. Catholic students reported the highest mean scores of $\mathrm{EE}(\mathrm{p}<0.05)$. Self-rated health was almost linearly associated with $\mathrm{EE}$ and $\mathrm{PA}$, signifying that the worse the self-rated health, the higher the burnout level ( $\mathrm{p}=0.000$ ). However, marital status, undergraduate major, financing of educational expense, drinking, smoking, and time sleeping were not associated with burnout level in the medical students (Table 3).

\section{Association between stressors and student burnout}

Multivariate regression analyses revealed that both educational stressors and relational stressors were significantly as-

Table 2. Burnout level of survey participants $(\mathrm{N}=263)$

\begin{tabular}{|c|c|c|c|c|c|c|c|c|c|}
\hline \multirow{2}{*}{ Burnout level } & \multicolumn{3}{|c|}{$\mathrm{EE}$} & \multicolumn{3}{|c|}{$\mathrm{DP}$} & \multicolumn{3}{|c|}{ PA } \\
\hline & Point range & $\mathrm{N}$ & $\%$ & Point range & $\mathrm{N}$ & $\%$ & Point range & $\mathrm{N}$ & $\%$ \\
\hline High & $19-28$ & 74 & 28.1 & $10-17$ & 105 & 40.4 & $4-14$ & 107 & 40.8 \\
\hline Moderate & $14-18$ & 122 & 46.4 & $8-9$ & 66 & 25.4 & $15-17$ & 73 & 27.9 \\
\hline Low & $0-13$ & 67 & 25.5 & $0-7$ & 89 & 34.2 & $18-26$ & 82 & 31.3 \\
\hline Missing & & & & & 3 & 1.1 & & 1 & 0.4 \\
\hline Total & & 263 & 100.0 & & 263 & 100.0 & & 263 & 100.0 \\
\hline
\end{tabular}

EE: emotional exhaustion, DP: depersonalization, PA: personal accomplishment

Table 3. Burnout by socio-demographics and health characteristics of survey participants $(\mathrm{N}=263)$

\begin{tabular}{|c|c|c|c|c|c|c|}
\hline \multirow{2}{*}{ Factors (statistics) } & \multicolumn{2}{|c|}{$\mathrm{EE}$} & \multicolumn{2}{|c|}{$\mathrm{DP}$} & \multicolumn{2}{|c|}{ PA } \\
\hline & Mean (SD) & $\mathrm{p}$-value & Mean (SD) & $\mathrm{p}$-value & Mean (SD) & $\mathrm{p}$-value \\
\hline Sex (t-test) & & 0.007 & & 0.389 & & 0.021 \\
\hline Male & $15.0(4.9)$ & & $8.4(3.2)$ & & $16.0(3.5)$ & \\
\hline Female & $16.6(4.5)$ & & $8.7(3.2)$ & & $15.0(3.4)$ & \\
\hline School year (ANOVA) & & 0.035 & & 0.025 & & 0.379 \\
\hline 1 st & $15.0(5.0)$ & & $7.7(3.0)$ & & $16.0(3.6)$ & \\
\hline 2nd & $16.7(4.9)$ & & $9.2(3.3)$ & & $15.7(3.7)$ & \\
\hline $3 \mathrm{rd}$ & $16.5(4.3)$ & & $8.4(3.5)$ & & $15.3(3.3)$ & \\
\hline 4 th & $14.7(4.7)$ & & $8.9(2.7)$ & & $14.9(3.2)$ & \\
\hline Religion (ANOVA) & & 0.034 & & 0.495 & & 0.579 \\
\hline Buddhism & $14.0(3.9)$ & & $7.9(2.7)$ & & $14.6(3.0)$ & \\
\hline Christianity & $15.1(5.2)$ & & $8.4(3.5)$ & & $15.6(3.8)$ & \\
\hline Catholic & $17.1(4.6)$ & & $9.2(3.5)$ & & $15.7(2.9)$ & \\
\hline Other & $13.5(0.7)$ & & $10.0(0.0)$ & & $13.5(0.7)$ & \\
\hline No religiosity & $16.4(4.7)$ & & $8.6(3.0)$ & & $15.8(3.6)$ & \\
\hline Self-rated health (ANOVA) & & 0.000 & & 0.525 & & 0.000 \\
\hline Very good & $13.1(5.4)$ & & $8.2(3.0)$ & & $16.4(3.5)$ & \\
\hline Good & $15.2(4.5)$ & & $8.3(3.3)$ & & $16.0(3.2)$ & \\
\hline Neutral & $17.0(3.8)$ & & $8.9(3.4)$ & & $15.4(3.2)$ & \\
\hline Bad & $19.9(4.5)$ & & $9.4(2.1)$ & & $12.5(4.6)$ & \\
\hline Very bad & $19.3(10.3)$ & & $9.0(3.6)$ & & $9.7(4.0)$ & \\
\hline
\end{tabular}

ANOVA: analysis of variance, EE: emotional exhaustion, DP: depersonalization, PA: personal accomplishment 
sociated with the risk of burnout among medical students. To preserve statistical power, only four factors were included as control variables, specifically, the factors significantly associated with burnout at the bivariate analyses. Educational stressors and relational stressors significantly increased EE and DP and decreased PA after controlling for other variables, thus supporting Hypothesis 1. In other words, levels of all the burnout dimensions-EE, DP, and PA-increased along with the increase in educational and relational stress levels. The standardized coefficients (Beta) indicate the relative impact of the independent variables on the dependent variable. Betas showed that educational stressors had the strongest impact on EE, whereas relational stressors had the strongest impact on DP and PA (Table 4).

Hierarchical regression analyses examined whether social support moderates the relationship between stressors and the three dimensions of burnout using three models. In Model 1, only educational and relational stressors were input to examine whether the stressors are associated with the each dimension of burnout. In Model 2, educational and relational stressors as well as social support were separately input to examine whether all the stressors are associated with the risk of each dimension of burnout. Finally, in Model 3, an interaction of stressors and social support additionally were input to examine whether social support be a moderator between stressors and burnout. Analyses revealed that social support was significantly associated with all three dimensions of burnout in medical students. However, social support only moderated the relationship between educational stressors and PA. In Model 1, educational and relational stressors significantly decreased PA, whereas social support significantly increased PA in Model 2. Meanwhile, an interaction of educational stressors and social support decreased PA in Model 3, signifying that social support moderated the association between educational stressors and PA of medical students. In other words, if medical students who experienced PA burnout received outside social support, they were likely to show a lower level of PA burnout. Social support, however, did not moderate the association between stressors and EE and DP, thus partially supporting Hypothesis 2 (Table 5).

\section{DISCUSSION}

Although the prevalence of burnout among medical students has been well documented in other countries, ${ }^{2,20-22}$ there has been no such study conducted in Korea. The current study is the first to report on burnout in Korean medical students. Our results show that Korean medical students report greater risk of burnout when defining burnout as high mean scores on EE or DP. ${ }^{2,23}$ The proportion of Korean medical students with EE burnout (28.1\%) in the present study is lower than that observed in the USA (34.7\%) but higher than the UK $(12.9 \%)^{21}$ and Spain $(17.8 \%) .{ }^{20}$ Furthermore the proportion of Korean medical students with DP burnout (40.4\%) is higher than that in the USA $(25.8 \%),{ }^{2}$ the UK $(7.1 \%),{ }^{21}$ and Spain $(10.0 \%) .{ }^{20}$ There are differences in the curriculum and the demography of medical students across countries. Most medical schools, including those in Korea, have a similar curriculum to that of the United States, which requires a preliminary Bachelor's degree. ${ }^{2}$ However, in the UK and Spain, students begin their medical studies without any preliminary higher education. ${ }^{13,20,21}$ Medical schools in Korea and in Ameri-

Table 4. Multivariate regression analyses on burnout with socio-demographics, self-rated health, and stressors

\begin{tabular}{|c|c|c|c|c|c|c|c|c|c|}
\hline \multirow{2}{*}{ Factors } & \multicolumn{3}{|c|}{$\mathrm{EE}$} & \multicolumn{3}{|c|}{ DP } & \multicolumn{3}{|c|}{ PA } \\
\hline & $\mathrm{b}$ & Beta & $\mathrm{p}$-value & $\mathrm{b}$ & Beta & $\mathrm{p}$-value & $\mathrm{b}$ & Beta & p-value \\
\hline (Constant) & -1.592 & & 0.482 & 6.045 & & 0.000 & 39.407 & & 0.000 \\
\hline Female & 0.274 & 0.015 & 0.736 & 0.055 & 0.006 & 0.927 & -0.961 & -0.081 & 0.160 \\
\hline School year & 0.301 & 0.038 & 0.408 & 0.466 & 0.107 & 0.084 & -0.356 & -0.067 & 0.245 \\
\hline Buddhism & -2.403 & -0.079 & 0.094 & -1.198 & -0.073 & 0.257 & -1.578 & -0.078 & 0.190 \\
\hline Christianity & -0.344 & -0.018 & 0.710 & -0.041 & -0.004 & 0.952 & -0.250 & -0.020 & 0.749 \\
\hline Catholic & 0.034 & 0.001 & 0.977 & 0.810 & 0.059 & 0.362 & 0.413 & 0.025 & 0.680 \\
\hline Self-rated health & 2.160 & 0.208 & 0.000 & 0.048 & 0.008 & 0.893 & -1.307 & -0.188 & 0.001 \\
\hline Educational stressors & 0.874 & 0.601 & 0.000 & 0.116 & 0.148 & 0.022 & -0.159 & -0.164 & 0.006 \\
\hline Relational stressors & 0.553 & 0.162 & 0.000 & 0.484 & 0.257 & 0.000 & -0.750 & -0.328 & 0.000 \\
\hline Number & \multicolumn{3}{|c|}{255} & \multicolumn{3}{|c|}{253} & \multicolumn{3}{|c|}{254} \\
\hline Model fitness & \multicolumn{3}{|c|}{$\mathrm{F}=33.751, \mathrm{p}=0.000$} & \multicolumn{3}{|c|}{$\mathrm{F}=4.226, \mathrm{p}=0.000$} & \multicolumn{3}{|c|}{$\mathrm{F}=10.001, \mathrm{p}=0.000$} \\
\hline Adjusted $\mathrm{R}^{2}$ & \multicolumn{3}{|c|}{0.507} & \multicolumn{3}{|c|}{0.093} & \multicolumn{3}{|c|}{0.221} \\
\hline
\end{tabular}

*reference group is "male" for sex, "no religion" for religion, and "very bad" for self-rated health. EE: emotional exhaustion, DP: depersonalization, PA: personal accomplishment 
Table 5. Hierarchical regression analyses on personal accomplishment with stressors and social support ( $\mathrm{N}=254)$

\begin{tabular}{|c|c|c|c|c|c|c|c|c|c|}
\hline \multirow{2}{*}{ Factors } & \multicolumn{3}{|c|}{ Model 1} & \multicolumn{3}{|c|}{ Model 2} & \multicolumn{3}{|c|}{ Model 3} \\
\hline & $\mathrm{b}$ & Beta & $\mathrm{p}$-value & $\mathrm{b}$ & Beta & $\mathrm{p}$-value & $\mathrm{b}$ & Beta & p-value \\
\hline (Constant) & 34.974 & & 0.000 & 25.281 & & 0.000 & 26.747 & & 0.000 \\
\hline Educational stressors & -0.176 & -0.181 & 0.002 & -0.177 & -0.182 & 0.001 & -0.197 & -0.203 & 0.000 \\
\hline Relational stressors & -0.851 & -0.372 & 0.000 & -0.625 & -0.273 & 0.000 & -0.633 & -0.276 & 0.000 \\
\hline Social support & & & & 0.234 & 0.285 & 0.000 & 0.209 & 0.337 & 0.000 \\
\hline $\begin{array}{l}\text { Educational stressors } \times \\
\text { social support }\end{array}$ & & & & & & & -0.014 & -0.128 & 0.029 \\
\hline $\begin{array}{l}\text { Relational stressors } \times \\
\text { social support }\end{array}$ & & & & & & & 0.008 & 0.086 & 0.647 \\
\hline Model fitness & \multicolumn{3}{|c|}{$\mathrm{F}=28.724, \mathrm{p}=0.000$} & \multicolumn{3}{|c|}{$\mathrm{F}=28.338, \mathrm{p}=0.000$} & \multicolumn{3}{|c|}{$F=18.166, p=0.000$} \\
\hline Adjusted $\mathrm{R}^{2}$ & \multicolumn{3}{|c|}{0.179} & \multicolumn{3}{|c|}{0.246} & \multicolumn{3}{|c|}{0.254} \\
\hline
\end{tabular}

ca emphasize clinical practice at the graduate level for students with the Bachelor's degree; ${ }^{2}$ this could explain why the level of burnout in Korea and America is higher than that of European countries. Most studies of burnout in medical students in the USA have considered burnout as high scores on EE or DP., ${ }^{2,4,15}$ Previous research has noted that medical students develop a sense of PA as they progress through medical school, which appears to counterbalance the burnout resulting from $\mathrm{EE}$ and $\mathrm{DP}^{18}$ While the PA scale can distinguish between people who are clinically burned out and those who are not, students were considered to have burnout symptoms if they scored highly on the DP or EE subscales of the MBI. ${ }^{15}$

Levels of EE are higher than DP in other countries. ${ }^{20,24}$ In the present study, however, levels of DP were higher than EE. Although DP was higher than EE in the total sample, the level of EE was not different among fourth-year students in the present study; this was similar to the findings among medical students in the USA. ${ }^{24}$ In the present study, the students reported EE burnout (28.1\%), DP burnout (40.4\%), and PA burnout (40.8\%). In a seven-institution study in the USA, $40.1 \%$ had high EE, $31.8 \%$ had high DP, and $30.6 \%$ had a low sense of PA. ${ }^{4}$ Although a low sense of PA was not considered as burnout in medical students, low PA was present in 30.6$52.0 \%$ of medical students in the USA.,24 The EE level of medical students in the USA is higher compared to our study, which found higher levels of DP burnout and PA burnout. However, the high level of PA burnout in our study is similar to one study conducted in the USA that reported $52.1 \%$ of students with PA burnout. ${ }^{24}$ In Korean medical schools, medical students rotate through clinical departments during their third and fourth years of training, and medical students as observers are not allowed to participate directly in providing patient care as do medical students in Spain..$^{20}$ Therefore, the higher level of PA burnout in our study might be associated with the observer or bystander role of medical students with- out direct practice and patient care.

There is considerable variability in how researchers have defined burnout. ${ }^{25}$ In the present study, $9.9 \%$ of medical students were "totally burned out" according to the three subscales, using a definition of burnout as having a high score on both $\mathrm{EE}$ and DP and a low score on PA on the MBI; this could result in an underestimation of burnout. ${ }^{17,18}$ The level of burnout on the three subscales, $9.9 \%$, is lower than the level of mild depression, $15.9 \%$, among Korean medical students. ${ }^{25}$ As burnout is a predictor of depression, it is acceptable to use only EE and DP measures, as other studies do. Nevertheless, as Korean medical students must pass clinical practice for qualification of the National Licensing Examination, it is meaningful to examine the PA burnout level of medical students.

Longitudinal studies consistently show higher rates of burnout, depression, and suicidal ideation in second-, third-, and fourth-year students than in first-year students. ${ }^{4,23,24,26}$ Longitudinal study among Korean first- and second-year medical students shows that depression and anxiety increase significantly over the year, irrespective of academic year. ${ }^{25}$ In the present study, there were no significant differences in the rate of burnout risk in terms of EE and PA among fourth-year medical students, but the burnout risks in terms of the DP subscale in second-year and fourth-year students were higher than in first-year and third-year students. This might be related to the frequency of exams in the second-year and fourthyear curricula. The second-year students must take 16 exams in one year, and the fourth-year students must prepare for the National Licensing Examination. Longitudinal study is needed to further identify more accurate relationships between school year and burnout level among medical students.

Main sources of distress in medical students are the learning environment and study conditions. ${ }^{13,27}$ Dissatisfaction with the learning environment is strongly correlated with burnout. ${ }^{27}$ Academic factors such as an overly extensive cur- 
riculum, frequent examinations, and homework overload can act as catalysts for burnout. ${ }^{28,29}$ Educational stressors are more strongly associated with burnout in terms of $\mathrm{EE}$, whereas relational stressors are more strongly related with burnout in terms of PA. Levels of EE and DP are related to the faculty or peers, discrimination, or alienation. ${ }^{22,29}$ In the present study, educational and relational stressors were also significantly related to the risk of burnout in medical students after controlling for socio-demographics and health characteristics. Overcompetitiveness and performance-driven academic conditions in Korean medical schools ${ }^{25}$ lead to medical students having higher DP and discord with others. The specific learning environment characteristics most strongly related to burnout vary between preclinical and clinical students. ${ }^{27}$ However, our results showed no difference in burnout risk between preclinical and clinical students. The difference was present in the roles of medical students in Korea as observers versus active learners during clinical training in the USA.

Besides educational and relational stressors, socio-demographic and health behaviors are significantly associated with burnout level in medical students. ${ }^{24,27,28}$ Conflicting results have been reported with regard to the relationship between gender and burnout. ${ }^{172,24,27,28}$ Burnout in terms of DP is more frequent in male students than in female students, ${ }^{24}$ although no difference has been observed in female and male students in Spain. ${ }^{19}$ In the present study, female students had high scores on EE. Female students showed significantly higher levels of EE and DP burnout in a previous study. ${ }^{10}$ This result may be associated with coping strategies of female students in medical schools. Female medical students have reported higher stress scores as well as higher use of emotion-focused coping strategies than male students. ${ }^{29}$

Roman-Catholic students had the highest scores on EE, whereas Buddhist students showed the lowest scores on EE. Self-rated health was significantly associated with EE and PA burnout but not with DP, signifying that the worse the health status, the higher the burnout. Another plausible explanation is that burnout might affect the health status of medical students.

The present study found that social support is a moderator between stressors and PA. Medical students who received help or social support coped well with psychological problems and burnout. ${ }^{15,28}$ Social support played a crucial role in buffering the stressors on PA burnout of medical students in the present study. PA was highest among the first-year students, suggesting that intervention programs might be of most benefit if initiated in the first year. ${ }^{27}$ Therefore, early signs of burnout in medical students should be detected in a timely way, and appropriate measures should be taken to mitigate stressors, especially educational stressors contributing to
PA burnout. Scholars have emphasized the need for organizational and individual interventions to avoid burnout. ${ }^{13}$ Students should be encouraged to utilize adequate facilities and counseling services to get help. One study reported that physicians who attended a counseling intervention for burnout significantly reduced their levels of emotional exhaustion, job stress, and emotion-focused coping strategies..$^{30}$ More studies are needed on creating a learning environment that cultivates student well-being.

The present study has several limitations. One is that the present study cannot overcome the definitional problem of burnout. There is considerable variability in the definition of burnout in the research literature. Defining burnout as having a high score on both EE and DP and a low score on PA on the MBI can result in an underestimation of burnout. ${ }^{12}$ This study was a cross-sectional study conducted in one medical school, and it is thus difficult to directly compare burnout level of other countries. Second, this study was conducted with a cross-sectional design and therefore, definite conclusions cannot be drawn as to the predictors of burnout; we can only infer the association with burnout. Third, since this study was based on a single medical school, the results might not be representative of other medical students in other universities in South Korea.

Nevertheless, the present study has several important points. First, this is the first study to investigate the risk of burnout in medical students in South Korea. Furthermore, our study provides some information about stressors, social support, and burnout in medical students. In conclusion, the burnout level is notably high among Korean medical students. Our results showed that educational and relational stressors as well as social support are significantly associated with burnout risk in medical students. Further studies are needed on detection of early burnout symptoms in medical students and how best to help them with appropriate social support.

\section{Supplementary Materials}

The online-only Data Supplement is available with this article at http://dx.doi.org/10.4306/pi.2015.12.4.451.

\section{REFERENCES}

1. Dyrbye LN, Thomas MR, Eacker A, Eacker A, Harper W, Massie FS Jr, et al. Race, ethnicity, and medical student well-being in the United States. Arch Intern Med 2007;167:2103-2109.

2. Dyrbye LN, Thomas MR, Huntington JL, Lawson KL, Novotny PJ, Sloan JA, et al. Personal life events and medical student burnout: a multicenter study. Acad Med 2006;81:374-384.

3. Dyrbye LN, Thomas MR, Shanafelt TD. Systematic review of depression, anxiety, and other indicators of psychological distress among U.S. and Canadian medical students. Acad Med 2006;81:354-373.

4. Dyrbye LN, Thomas M, Massie FS, Power DV, Eacker A, Harper W, et al. Burnout and suicidal ideation among US medical students. Ann Intern Med 2008;149:334-341. 
5. Roh MS, Jeon HJ, Kim H, Cho HJ, Han SK, Hahm BJ. Factors influencing treatment for depression among medical students: a nationwide sample in South Korea. Med Educ 2009;43:133-139.

6. Aktekin M, Karaman T, Senol YY, Erdem S, Erengin H, Akaydin M. Anxiety, depression and stressful life events among medical students: a prospective study in Antalya, Turkey. Med Educ 2001;35:12-17.

7. Lubitz RM, Nguyen DD. Medical student abuse during third-year clerkships. JAMA 1996;275:414-416.

8. Yussuf AD, Issa BA, Ajiboye PO, Buhari OI. The correlates of stress, coping styles and psychiatric morbidity in the first year of medical education at a Nigerian University. Afr J Psychiatry (Johannesbg) 2013;16: 206-215.

9. Dyrbye LN, Thomas MR, Harper W, Massie FS Jr, Power DV, Eacker A, et al. The learning environment and medical student burnout: a multicentre study. Med Educ 2009;43:274-282.

10. Fuss I, Nubling M, Hasselhorn HM, Schwappach D, Rieger MA. Working conditions and work-family conflicts in German hospital physicians: psychosocial and organizational predictors and consequences. BMC Public Health 2008;8:353.

11. Kim SH, Jeon WT. The failure experiences of medical school students; a qualitative study. Korean J Med Educ 2008;20:351-362.

12. Maslach C, Shaufeli WB, Leiter MP. Job burnout. Annu Rev Psychol 2001;52:397-422.

13. Dahlin M, Joneborg N, Runeson B. Performance-based self-esteem and burnout in a cross-sectional study of medical students. Med Teach 2007; 29:43-48.

14. Paro HB, Silveria PS, Perotta B, Gannam S, Enns SC, Giaxa RR, et al. Empathy among medical students: Is there a relation with quality of life and burnout? PLoS ONE 2014;9:e94133.

15. Dyrbye LN, Power DV, Massie FS, Eacker A, Harper W, Thomas MR, et al. Factors associated with resilience to and recovery from burnout: a prospective, multi-institutional study of US medical students. Med Educ 2010;44:1016-1026.

16. Zimet GD, Dahlem NW, Zimet SG, Farley GK. The multidimensional Scale of Perceived Social Support. J Pers Assess 1988;52:30-41.

17. Santen SA, Holt DB, Kemp JD, Hemphill RR. Burnout in medical students: examining the prevalence and associated factors. South Med J 2010;103:758-763.
18. Brenninkmeijer V, Van Yperen N. How to conduct research on burnout: advantages and disadvantages of a unidimensional approach in burnout research. Occup Environ Med 2003;60(Suppl 1):i16-i20.

19. Maslach C, Jackson SE, Leiter MP. Maslach Burnout Inventory Manual. 3rd Edition. Palo Alto, CA; Consulting Psychologists Press: 2004.

20. Galán F, Sanmartín A, Polo J, Giner L. Burnout risk in medical students in Spain using the Maslach Burnout Inventory-Student survey. Int Arch Occup Environ Health 2011;84:453-459.

21. Guthrie E, Black D, Bagalkote H, Shaw C, Campbell M, Creed F. Psychological stress and burnout in medical students: a five-year prospective longitudinal study. J R Soc Med 1998;91:237-243.

22. Prins JT, Gazendam-Donofrio SM, Dillingh GS, van de Wiel HB, van der Heijden FM, Hoekstra-Weebers JE. The relationship between reciprocity and burnout in Dutch medical residents. Med Educ 2008;42: 721-728.

23. Willcock SM, Daly MG, Tannant CC, Allard BJ. Burnout and psychiatric morbidity in new medical graduates. Med J Aust 2004;181:357-360.

24. Chang E, Eddines-Folensbee F, Coverdale J. Survey of the prevalence of burnout, stress, depression, and the use of support by medical students at one school. Acad Psychiatry 2012;36:177-182.

25. Prins JT, Gazendam-Donofrio SM, Tubben BJ, Van der Heijden FM, Van de Wiel HB, Hoekstra-Weebers JE. Burnout in medical residents: a review. Med Educ 2007;41:788-800.

26. Rosal MC, Ockene IS, Ockene JK, Barrett SV, Ma Y, Hebert JR. A longitudinal study of students' depression at one medical school. Acad Med 1997;72:542-546.

27. Dyrbye LN, Thomas MR, Huschka MM, Lawson KL, Novotny PJ, Sloan JA, et al. A multicenter study of burnout, depression, and quality of life in minority and nonminority US medical students. Mayo Clin Proc 2006;81:1435-1442.

28. Isaksson Ro KE, Tyssen R, Hoffart A, Sexton H, Aasland OG, Gude T. A three-year cohort study of the relationships between coping, job stress and burnout after a counseling intervention for help-seeking physicians. BMC Public Health 2010;10:213.

29. Jones FM, Fellows JL, Horne DJ. Coping with cancer: a brief report on stress and coping strategies in medical students dealing with cancer patients. Psychooncology 2011;20:219-223. 